\title{
Combined Anterior-Posterior Surgery Versus Posterior Surgery for Thoracolumbar Burst Fractures: A Systematic Review of the Literature
}

\author{
Pim P. Oprel*, Wim E. Tuinebreijer, Peter Patka and Dennis den Hartog \\ Department of Surgery-Traumatology, Erasmus MC, University Medical Center Rotterdam, 's-Gravendijkwal 230, 3015 \\ CE Rotterdam, The Netherlands
}

\begin{abstract}
Study Design: A systematic quantitative review of the literature.
Objective: To compare combined anterior-posterior surgery versus posterior surgery for thoracolumbar fractures in order to identify better treatments.

Summary of Background Data: Axial load of the anterior and middle column of the spine can lead to a burst fracture in the vertebral body. The management of thoracolumbar burst fractures remains controversial. The goals of operative treatment are fracture reduction, fixation and decompressing the neural canal. For this, different operative methods are developed, for instance, the posterior and the combined anterior-posterior approach. Recent systematic qualitative reviews comparing these methods are lacking.

Methods: We conducted an electronic search of MEDLINE, EMBASE, LILACS and the Cochrane Central Register for Controlled Trials.

Results: Five observational comparative studies and no randomized clinical trials comparing the combined anteriorposterior approach with the posterior approach were retrieved. The total enrollment of patients in these studies was 755 patients. The results were expressed as relative risk (RR) for dichotomous outcomes and weighted mean difference (WMD) for continuous outcomes with $95 \%$ confidence intervals (CI).

Conclusions: A small significantly higher kyphotic correction and improvement of vertebral height (sagittal index) observed for the combined anterior-posterior group is cancelled out by more blood loss, longer operation time, longer hospital stay, higher costs and a possible higher intra- and postoperative complication rate requiring re-operation and the possibility of a worsened Hannover spine score. The surgeons' choices regarding the operative approach are biased: worse cases tended to undergo the combined anterior-posterior approach.
\end{abstract}

Keywords: Systematic review, outcome, burst fracture, thoracolumbar spine, technique, surgery.

\section{INTRODUCTION}

The thoracolumbar region of the spine consists of the region extending from the eleventh thoracic vertebra to the second lumbar vertebra (T11 to L2). Trauma may lead to fractures of this part of the spine. The average annual incidence of spinal fracture is 63.6 per 100,000 [1]. Forty-six percent of these fractures are admitted to the hospital (incidence of 29 per 100,000 ) and $54 \%$ are seen in an ambulatory setting. Among the hospitalized patients, $60 \%$ are men. An accidental fall is the most frequent cause of injury and motor vehicle and transport injury are the second most frequent [1, 2]. In a retrospective study of 412 thoracolumbar injuries, Denis introduced a classification system based on the biomechanical concept of the three columns [3]. The anterior column is formed by the anterior longitudinal ligament, the anterior annulus fibrosus and the anterior part of the vertebral body. The middle column is formed by the posterior longitudinal ligament, the posterior

*Address correspondence to this author at the Department of SurgeryTraumatology, Erasmus MC, University Medical Center Rotterdam, 'sGravendijkwal 230, Office H-815, 3015 CE Rotterdam, The Netherlands; Tel: +31 10 7032395; Fax +31 10 7032396; E-mail: p.oprel@erasmusmc.nl annulus fibrosus and the posterior part of the vertebral body. The posterior column is formed by the posterior arch and the posterior ligamentous complex. Failure of the vertebral body under axial load can cause a burst fracture. In a burst fracture, the anterior and middle column are fractured, leading to retropulsion of a posterior vertebral body fragment in the spinal canal. This bone fragment can be the cause of neural injury. This type of fracture is unstable. In the Denis study, 59 of the 412 case were burst fractures (14\%) [3]. Most burst fractures were lumbar (86\%). Twenty-eight (47.5\%) patients among the 59 patients presenting burst fractures had neurological deficits. Only one patient had complete paraplegia: The neurological deficits were mostly incomplete, but neurological deterioration may evolve in this condition.

Different operative methods exist with the goals of fracture reduction, fixation and decompressing the neural canal. These stabilization procedures can be divided in anterior, posterior and combined anterior-posterior instrumentation. Systematic reviews comparing exclusively posterior approaches and combined anterior-posterior approaches have not been done. A recent Cochrane review compared operative versus non-operative treatment for thoracolumbar burst fractures without neurological deficit 
[4]. A recent literature review examining the outcomes of the different surgical procedures for thoracic and lumbar spine did not statistically compare the different techniques, because of preoperative inequality of the patients with regard to injury severity [5]. For this reason, we wanted to perform a systematic literature review for studies describing randomized controlled trials and/or comparative studies comparing the combined anterior-posterior with the posterior instrumentation technique.

The primary objective of this review is to compare the combined anterior-posterior with the posterior instrumentation technique for thoracolumbar burst fractures in order to identify the better treatment.

\section{MATERIALS AND METHODOLOGY}

We conducted an electronic search including MEDLINE, EMBASE, LILACS and the Cochrane Central Register of Controlled Trials (CENTRAL). We did not limit the search by language or publication date. We used the following search terms in different combinations as MeSH (Medical Subject Heading) terms and as text words: Spinal fractures, treatment outcome, surgery, controlled clinical trial, comparative study. Manual searches including reference lists of all included studies were used to identify trials that the electronic search may have failed to identify.

Two reviewers independently assessed the titles and abstracts of all reports identified by electronic and manual searches. Each report was labeled as (a) definitely exclude, (b) unsure or (c) definitely include. Full text articles of abstracts labeled as "unsure" were reassessed according to the inclusion criteria for this review. Any differences were resolved through discussion. Studies labeled as "definitely exclude" were excluded from the review, while studies labeled as "definitely include" were further assessed for methodological quality.

Two reviewers independently extracted the data for the primary and secondary outcomes and entered the data into data collection forms developed for this purpose. Discrepancies were resolved by consensus. All data were entered into Review Manager (RevMan, [Computer program. Version 5.0. Copenhagen: The Nordic Cochrane Centre, The Cochrane Collaboration, 2008]).

Two reviewers independently assessed the included studies for sources of systematic bias in trials. Differences between the two reviewers were resolved by discussion.

Dichotomous outcomes (e.g. presence/absence of pain) were reported as proportions and were directly compared (difference in proportions). We used these proportions to calculate risk ratios (RRs) with $95 \%$ confidence intervals (CIs). For continuous data (e.g., Cobb's angle in degrees, vertebral height), results are presented as weighted mean differences (WMD). We used Review Manager 5.0 software (RevMan 5.0, Cochrane software) for generating the figures and statistical analyses. We explored heterogeneity using the chi-squared test with significance set at a P-value less than 0.10 . The quantity of heterogeneity was estimated by the Isquared statistic. Because prior statistical evidence existed for homogeneity of effect sizes, the analysis used a fixed effect model.

\section{RESULTS}

No randomized controlled trials were retrieved. Five observational studies comparing anterior-posterior with posterior surgery were included with a total enrolment of 755 patients with available follow-up (Tables 1-5). Only two studies were prospective. The full text of every study was retrieved. All studies included patients with posterior and anterior-posterior surgical approach; one study also compared the quality of life of posterior and anteriorposterior surgical approach patients with the age-adjusted norm population. Observational studies that did not compare different treatments were excluded, because they provide a low level of evidence (level IV evidence, no control group). The results were expressed as relative risk (RR) for dichotomous outcomes and weighted mean difference (WMD) for continuous outcomes with 95\% confidence intervals (CI). For the following variables, data from different studies could be pooled: kyphotic correction (Cobb's angle in degrees), loss of kyphotic correction,

Table 1. Characteristics of the Study of Been et al. [8]

\begin{tabular}{|c|c|}
\hline Methods & Retrospective Observational Study. \\
\hline Participants & $\begin{array}{l}54 \text { thoracolumbar burst fractures, follow-up data from } \mathrm{N}=46(85 \%) \text {, time period May } 1986 \text { - October } 1993,>50 \% \text { narrowing spinal } \\
\text { canal on CT, operation }<30 \text { days of injury. CT-scan. }\end{array}$ \\
\hline Interventions & $\begin{array}{l}\text { Group I: Anterior decompression/stabilization with iliac bone graft }+ \text { posterior stabilization: } \mathrm{N}=27 \text {. Group II: Posterior distraction } \\
\text { instrumentation and stabilization wit } \mathrm{AO} \text { internal fixator: } \mathrm{N}=19 \text {. Brace for } 3 \text { months. Significantly more severe other traumatic injuries } \\
(58 \% \text { versus } 22 \%, \mathrm{P}<.005) \text { and significantly less fracture level at thoracolumbar junction in group I (group I } 70 \% \mathrm{~T} 12-\mathrm{L} 1 \text { versus } 32 \% \text { in } \\
\text { group II, } \mathrm{P}<.01) \text {, caused by selection criteria for operation. }\end{array}$ \\
\hline Outcomes & $\begin{array}{l}\text { Loss of reduction }>5^{0} \text { : group I N=2 }(7 \%) \text { versus group II N=13 }(68 \%), \mathrm{P}=.0013 \text {. At late follow-up demonstrated no difference in } \\
\text { kyphotic deformity, because of over correction in group II. Kyphotic angle: group I early postoperative mean } 1.2^{0}\left(\mathrm{SD}=5.5^{0}\right) \text { versus } \\
\text { group II mean }-4.1^{0}\left(\mathrm{SD}=9.9^{0}\right) \text {; group I late follow-up mean } 3.3^{0}\left(\mathrm{SD}=7.7^{0}\right) \text { versus group II mean } 4.1^{0}\left(\mathrm{SD}=12.4^{0}\right) . \mathrm{No} \text { difference in pain: } \\
\text { group I } 23 / 27 \text { no pain }(85 \%) \text {, group II } 15 / 19 \text { no pain }(68 \%) \text {. Infection in one case in both groups leading to posterior device removal. } \\
\text { Bony union was } 100 \% \text { in both groups. }\end{array}$ \\
\hline Notes & $\begin{array}{l}\text { Selection bias: Type of operation dependent on availability of instrumentation and presence of other severe organ injuries. Before } 1988 \text {, } \\
\text { all patients received the combined approach. After 1998, patients with multiple injuries received the posterior approach unless there was } \\
\text { major compression to the spinal canal by bone fragments + neurological impairment. No significant differences between groups for age, } \\
\text { sex, cause of injury or fracture classification (Denis). }\end{array}$ \\
\hline
\end{tabular}


Table 2. Characteristics of the Study of Briem et al. [9]

\begin{tabular}{|c|c|}
\hline Methods & Prospective Study, Patients Matched for Sex, Age and Radiological Patterns of Injury. \\
\hline Participants & $\begin{array}{l}20 \text { consecutive patients with single level traumatic burst fracture of the thoracolumbar transition (Th12-L2), time period } 1995-2000 \text {. } \\
\text { Follow-up posterior group } 47.5 \text { months (Standard error of the mean=SEM=9.2), combined group 29.7 months (SEM=2.7). Average age } \\
\text { of the combined group was } 49.6 \text { years ( } S E M=3.6 \text { ) versus mean age } 47.3 \text { years (SEM=3.5) for posterior stabilization. Groups were } \\
\text { matched for age, sex and radiological pattern of injury. }\end{array}$ \\
\hline Interventions & $\begin{array}{l}\mathrm{N}=10 \text {, combined procedure: primary dorsal stabilization with fixateur interne }+ \text { ventral fusion with autologous bone graft versus } \mathrm{N}=10 \\
\text { posterior stabilization with bi-segmental fixateur interne, no bone graft. }\end{array}$ \\
\hline Outcomes & $\begin{array}{l}\text { SF-36 quality of life questionnaire, no difference between combined and posterior groups. Both groups exhibited a reduced quality of life } \\
\text { (physical health) compared to age-referred normal population. Both groups postoperative significant reduction of Cobb's angle. During } \\
\text { follow-up non-significant loss of reduction between groups (combined mean Cobb angle } 2.8^{0}, \mathrm{SEM}=1.0^{0} \text { versus posterior mean } 2.1^{0} \text {, } \\
\mathrm{SEM}=1.6^{0} \text { ). Posterior group significant height loss vertebral body (saggital index) at } 4 \text { years (mean height } .88, \mathrm{SEM}=.02 \text { postoperative } \\
\text { versus mean } .77, \mathrm{SEM}=.03 \text { at } 4 \text { years, } \mathrm{P}=.001 \text { ). Combined group no significant height loss at } 2 \text { years (mean height } .85, \mathrm{SEM}=.02 \\
\text { postoperative versus mean } .82, \mathrm{SEM}=.02 \text { at } 2 \text { years, } \mathrm{P}>.05 \text { ). }\end{array}$ \\
\hline Notes & No significant correlation between SF-36 and age, loss of correction, Cobb angle and saggital index. \\
\hline
\end{tabular}

Table 3. Characteristics of the Study of Danisa et al. [6]

\begin{tabular}{|c|c|}
\hline Participants & $\begin{array}{l}49 \text { thoracolumbar burst fractures, incompletely paraplegic or neurologically normal plus one or more:1) }>50 \% \text { loss of vertebral height } \\
\text { measured on lateral radiograph, 2) }>20^{\circ} \text { kyphosis measured on lateral radiograph, 3) }>40 \% \text { canal encroachment seen on CT. Period: } 1 \text { - } \\
1-1990 \text { until 1-12-1993. Average follow-up } 27 \text { months (range } 6-54 \text { months). }\end{array}$ \\
\hline Interventions & $\begin{array}{l}\text { Anterior }(\mathrm{N}=16) \text { decompression of spinal canal and autograft or posterior }(\mathrm{N}=27) \text { or combined anterior-posterior approach }(\mathrm{N}=6) \text {. The } \\
\text { choice of surgical procedure was determined by attending physician. }\end{array}$ \\
\hline Outcomes & 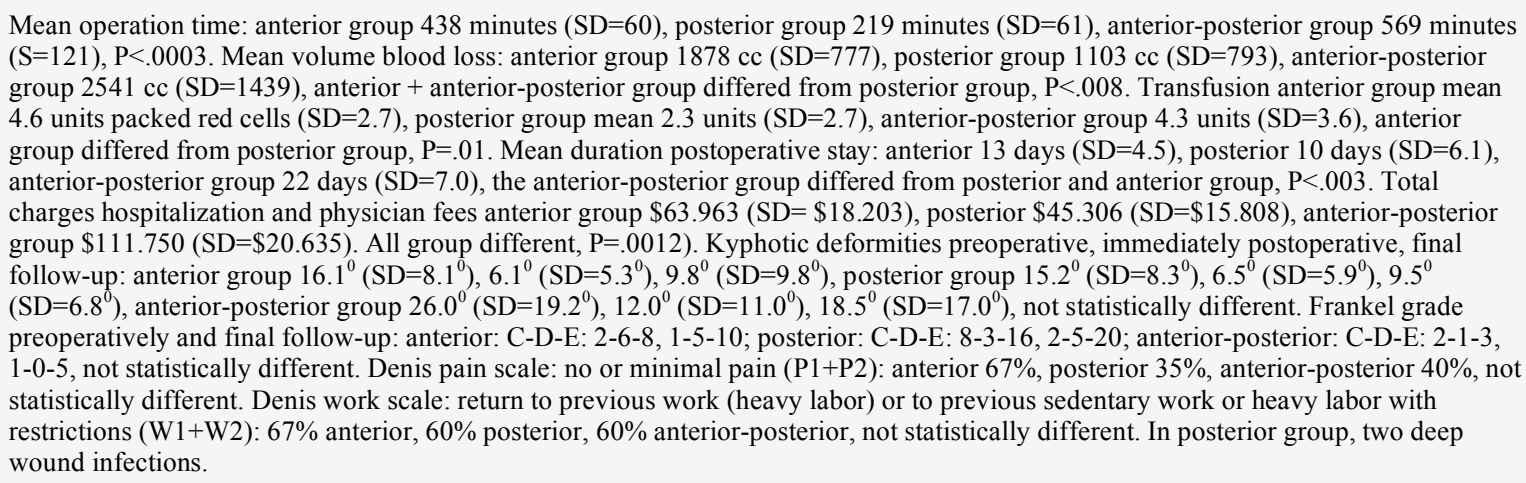 \\
\hline Notes & $\begin{array}{l}\text { Only } 6 \text { patients treated by combined anterior-posterior approach with an average of } 9.5 \text { days between procedures. Groups were similar } \\
\text { for age, gender, level of injury, \% of canal compromise, neurological function and kyphosis preoperatively. Retrospective study, no } \\
\text { RCT. The choice of surgical procedure was determined by attending physician. }\end{array}$ \\
\hline
\end{tabular}

percentage of patients with no or minimal pain at follow-up, height loss of vertebral body (sagittal index) at follow-up, return to previous employment and deep wound infection. The percentages of dichotomous outcomes were pooled with the Mantel-Haenszel statistical method and for continuous data, inverse variance statistical analysis was used. For this pooling, the fixed effects model was used since we assumed that all variation between the studies was caused by chance and that the studies measured the same overall effect. Even if a random-effects model was used, our conclusions remained the same. Data from the studies that used different outcome measures could not be pooled due to clinical and methodological heterogeneity, and thus are described individually.

\section{Anterior-Posterior Surgery Versus Posterior Surgery}

Two studies were pooled for the postoperative outcome measure kyphotic correction (Cobb's angle in degrees)
(Comparison 1.1: two studies; 678 participants; WMD 3.42, $95 \%$ CI 2.02 to $4.83 ; \mathrm{P}<.00001)[6,7]$. The contributing weight of the large study of Knop et al. was high $(98.7 \%)$. The postoperative kyphotic correction was significantly higher in the combined anterior-posterior group (Fig. 1).

Four studies were pooled for loss of kyphotic correction (Cobb's angle in degrees) (Comparison 1.2: four studies; 450 participants; WMD $0.27,95 \% \mathrm{CI}-1.11$ to $1.64 ; \mathrm{P}=.70)[6,8$ $10]$. The contributing weight of the large study of Knop et al. was high $(77.9 \%)$. The loss of kyphotic correction was not significantly different between the two approaches (Fig. 2).

Three studies were pooled for the percentage of patients with no or minimal pain at follow-up (Comparison 1.3: three studies; 90 participants; RR 1.21, 95\% CI 0.87 to 1.69 ; $\mathrm{P}=0.26)[6,8,11]$. The percentage of patients with no or minimal pain at follow-up was not significantly different between the two approaches (Fig. 3). 
Table 4. Characteristics of the Study of Knop et al. [7, 10]

\begin{tabular}{|c|c|}
\hline Methods & Prospective Multicenter Study, 18 Centers \\
\hline Participants & $\begin{array}{l}682 \text { patients with acute fractures/dislocations thoracolumbar spine (T10-L2), } 436 \text { male }(63.9 \%), 246 \text { female }(36.1 \%) \text {, mean age } 39.5 \\
\text { years (range } 7-83) \text {. Period September } 1994 \text { until December } 1996.144 \text { Patients }(21.1 \%) \text { neurological deficit. In combined versus } \\
\text { posterior group, significantly more fracture type } \mathrm{C}+\text { less fracture type A. In combined versus posterior group, more incomplete } \\
\text { neurological deficit and fewer patients without neurological deficit, no difference for complete paraplegia. No difference for associated } \\
\text { injuries and polytrauma. } \\
\text { Follow-up of outpatients: } \mathrm{N}=372(80 \%) \text {, mean } 27 \text { months (min. } 4 \text {, max. } 61 \text { months). At follow-up: in combined versus posterior group } \\
\text { significant more fracture type } \mathrm{C}+\text { less fracture type A. In combined versus posterior group no difference for incomplete neurological } \\
\text { deficit, for no neurological deficit and for complete paraplegia. Patients at follow-up with preoperative neurological deficit: posterior } \\
\text { group } 16 \% \text {, anterior-posterior group } 23 \%(\mathrm{P}=.14) \text {. No difference for associated injuries and polytrauma. }\end{array}$ \\
\hline Interventions & $\begin{array}{l}448 \text { posterior }(65.7 \%) \text {, anterior-posterior } 197(28.9 \%), 37 \text { anterior }(5.4 \%) \text { approach. Anterior-posterior: } 75 \text { ( } 38.1 \%) \text { one-stage, } 122 \\
(61.9 \%) \text { two-stage procedure. } \\
\text { Late follow-up: } 219 \text { posterior patients and } 132 \text { combined group patients. }\end{array}$ \\
\hline Outcomes & 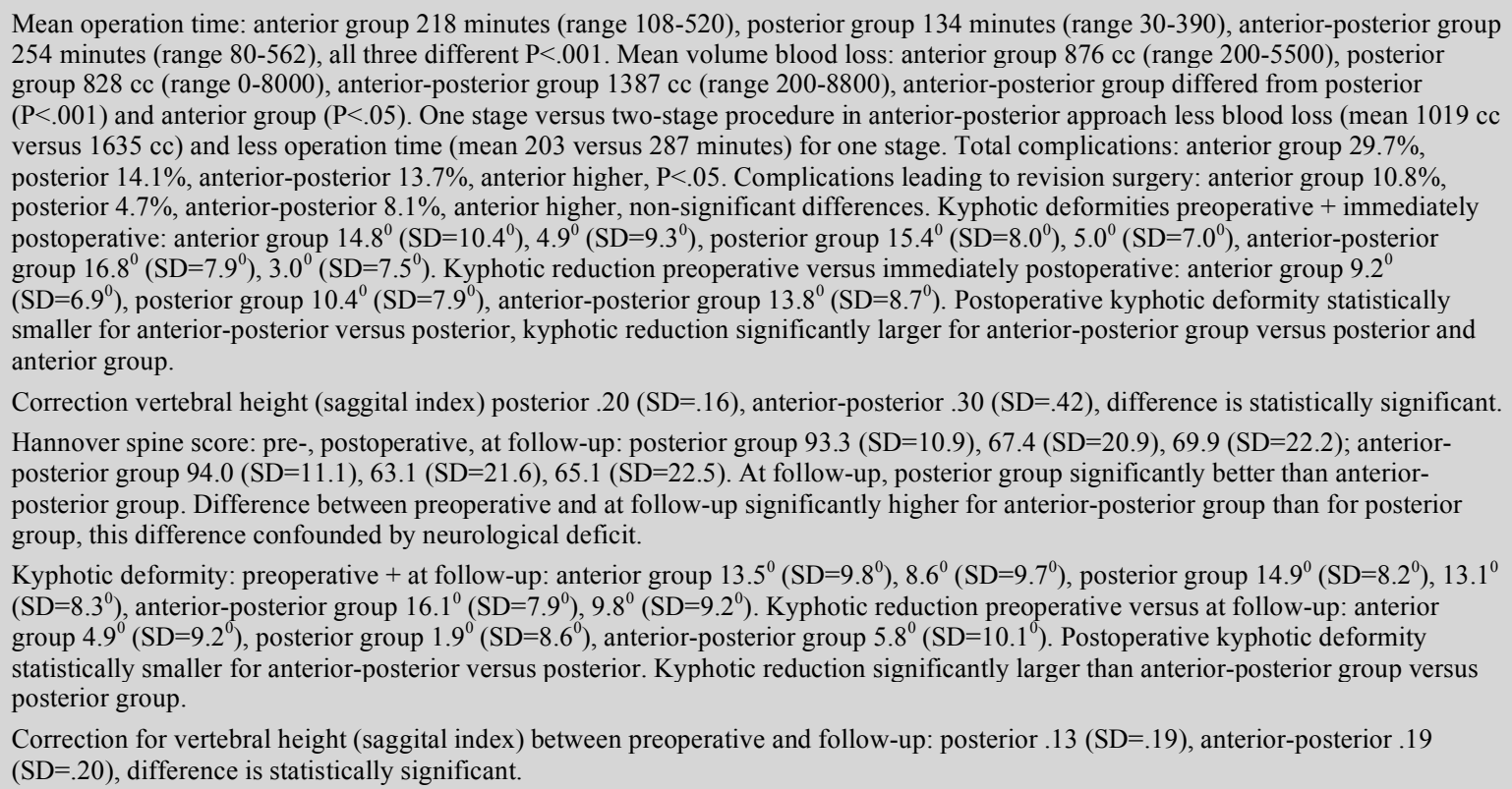 \\
\hline Notes & blood loss. \\
\hline
\end{tabular}

Table 5. Characteristics of the Schnee et al. Study [11]

\begin{tabular}{|c|c|}
\hline Methods & Retrospective Observational Study \\
\hline Participants & $\begin{array}{l}25 \text { ( } 18 \text { male, } 7 \text { female) patients, time period: } 1993-1995 \text {, mean age } 34.4 \text { years (range } 14-59 \text { years), associated injuries } n=21 \text {, mean } \\
\text { interval injury-operation } 4.7 \text { days (range 1-27 days). Clinical follow-up } 16.3 \text { months (range } 7-29.3 \text { ), radiographic follow-up } 8.8 \text { months } \\
\text { (range 3-19). }\end{array}$ \\
\hline Interventions & $\begin{array}{l}\mathrm{N}=14 \text { anterior: indication }>=40 \% \text { ventral canal compromise, }>=40 \% \text { loss of body height and } / \text { or }>=15^{0} \text { kyphosis, if no neurological } \\
\text { deficit present or presence of complete motor deficit no influence on indications for ventral approach, } \mathrm{N}=9 \text { combined anterior-posterior } \\
\text { (one procedure): indications for anterior }+ \text { multilevel corpectomies or posterior column injury unstable and } \mathrm{N}=2 \text { posterior approach: } \\
\text { indication }<40 \% \text { ventral canal compromise, no unstable neurological deficit or deformity. }\end{array}$ \\
\hline Outcomes & $\begin{array}{l}\text { Neurological outcome: Benzel-Larson grade, Frankel grade, Prolo economic and functional (pain) rating scale. The different approaches } \\
\text { were not compared statistically. Kyphotic deformities preoperative, immediately postoperative: anterior group } 16.8^{0}(0-45), 2.9^{0}(0-10) \text {, } \\
\text { posterior group } 7.5^{\circ}(5-10), 10^{\circ}(0-20) \text {, anterior-posterior group } 18.3^{0}(5-35), 1.0^{0}(0-5) \text {. Pain: posterior occasional } 0 / 2(0 \%) \text {, daily } 2 / 2 \\
(100 \%) \text {; combined group occasional } 8 / 9(89 \%) \text {, daily } 1 / 9(11 \%) \text {. Seven of } 9 \text { patients of combined group and } 2 \text { of } 2 \text { patients of posterior } \\
\text { group at follow-up returned to prior employment. Frankel grade preoperatively and final follow-up: anterior: B-C-D-E: } 2-2-4-6,1-1-4- \\
8 \text {; posterior: B-C-D-E: } 0-0-1-1,0-0-0-2 \text {; anterior-posterior: B-C-D-E: } 2-3-3-1,0-2-5-2 \text {. One deep wound infection in anterior-posterior } \\
\text { group. }\end{array}$ \\
\hline Notes & $\begin{array}{l}\text { Operative approach dependent on vertebral body height, canal compromise and kyphosis. From Prolo outcome scale, only mean and no } \\
\text { SD provided. From kyphotic deformity, only mean and range given without SD. }\end{array}$ \\
\hline
\end{tabular}




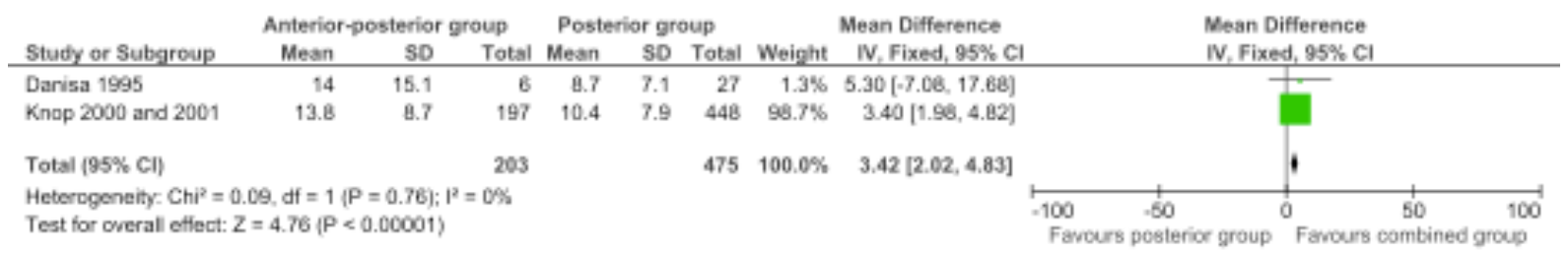

Fig. (1). Forest plot comparing anterior-posterior surgery versus posterior surgery for the outcome kyphotic correction (Cobb's angle in degrees).

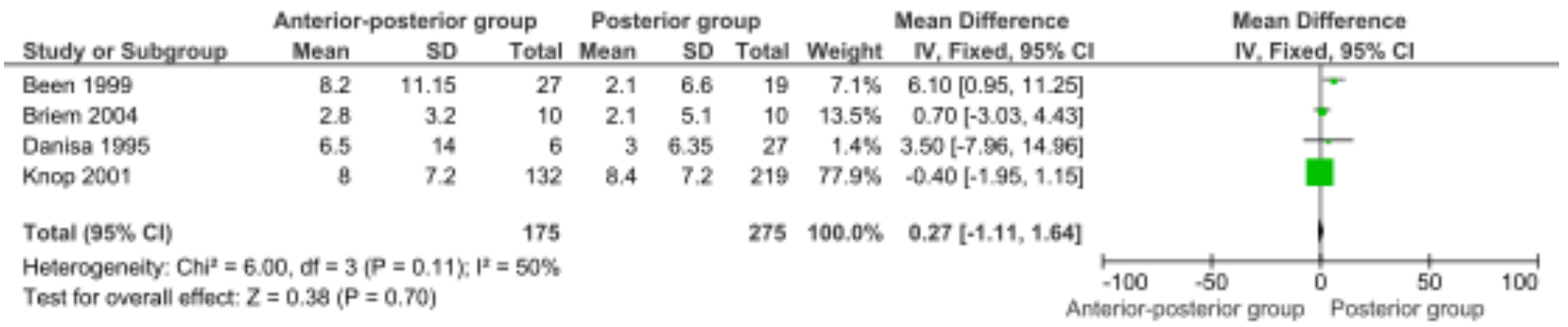

Fig. (2). Forest plot comparing anterior-posterior surgery versus posterior surgery for the outcome loss of kyphotic correction (Cobb's angle in degrees) during follow-up.

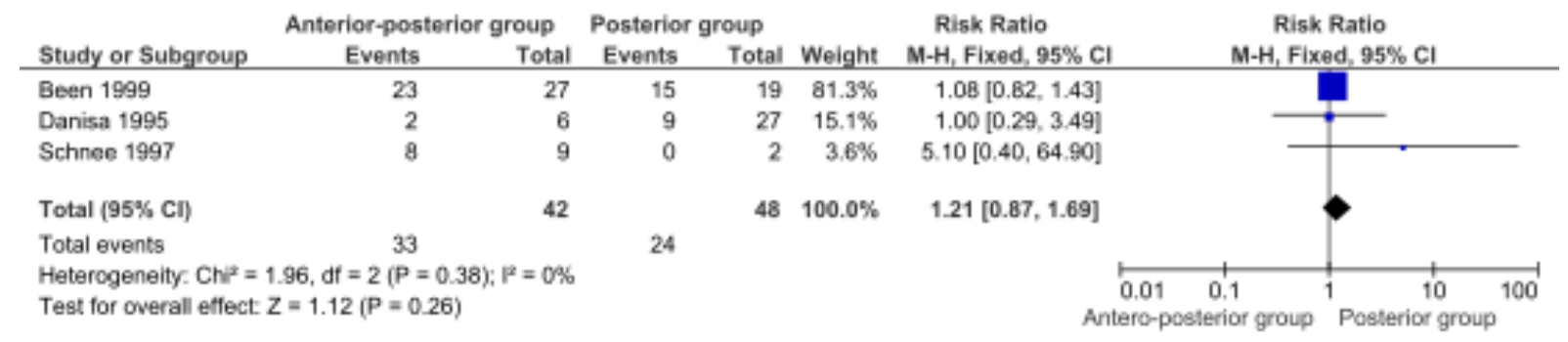

Fig. (3). Forest plot comparing anterior-posterior surgery versus posterior surgery for the outcome percentage of patients with no or minimal pain at follow-up.

The postoperative improvement of the vertebral height (saggital index) was only retrieved from one study (Comparison 1.4: One study; 645 participants; WMD 0.10, $95 \%$ CI 0.04 to $0.16 ; \mathrm{P}=.001$ ) [7]. The postoperative improvement of the vertebral height (saggital index) was significantly higher in the combined anterior-posterior group.

Two studies were pooled for height loss of the vertebral body (saggital index) between direct postoperative and final follow-up (Comparison 1.5: two studies; 371 participants; WMD $-0.01,95 \%$ CI -0.03 to $0.02 ; \mathrm{P}=.69)[9,10]$. The contributing weight of the large study by Knop et al. was high (83.1\%). The height loss of the vertebral body (saggital index) between direct postoperative and final follow-up was not significantly different between the two approaches (Fig. 4).
The operative time in minutes was only retrieved from one study (Comparison 1.6: one study; 33 participants; WMD $350.0,95 \%$ CI 250.49 to $449.51 ; \mathrm{P}<.00001$ ) [6]. The operative time in minutes was significantly longer in the combined anterior-posterior group.

The mean volume blood loss in cc was only retrieved from one study (Comparison 1.7: one study; 33 participants; WMD $1438.0,95 \%$ CI 248.36 to $2627.64 ; \mathrm{P}=.02$ ) [6]. The mean volume blood loss in cc was significantly higher in the combined anterior-posterior group.

The postoperative hospital stay in days was only retrieved from one study (Comparison 1.8: one study; 33 participants; WMD 12.0, 95\% CI 5.94 to $18.06 ; \mathrm{P}=.0001$ ) [6]. The postoperative hospital stay in days was significantly longer in the combined anterior-posterior group.

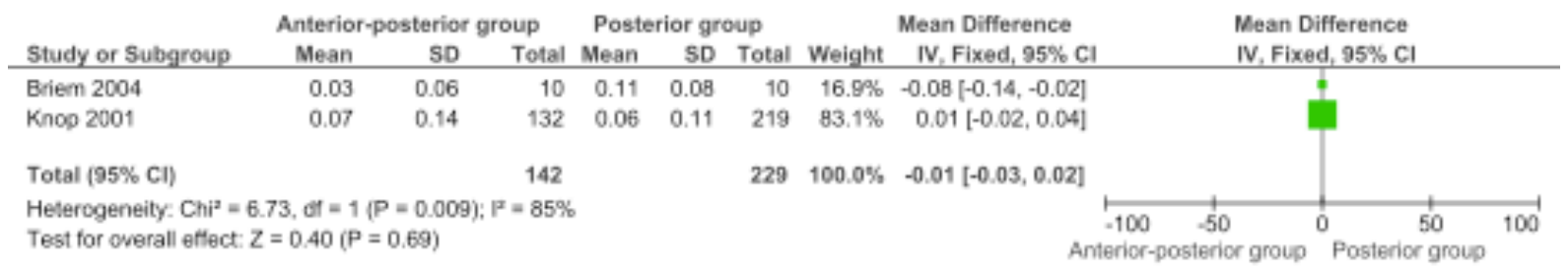

Fig. (4). Forest plot comparing anterior-posterior surgery versus posterior surgery for the outcome height loss vertebral body (saggital index) between postoperative and final follow-up. 


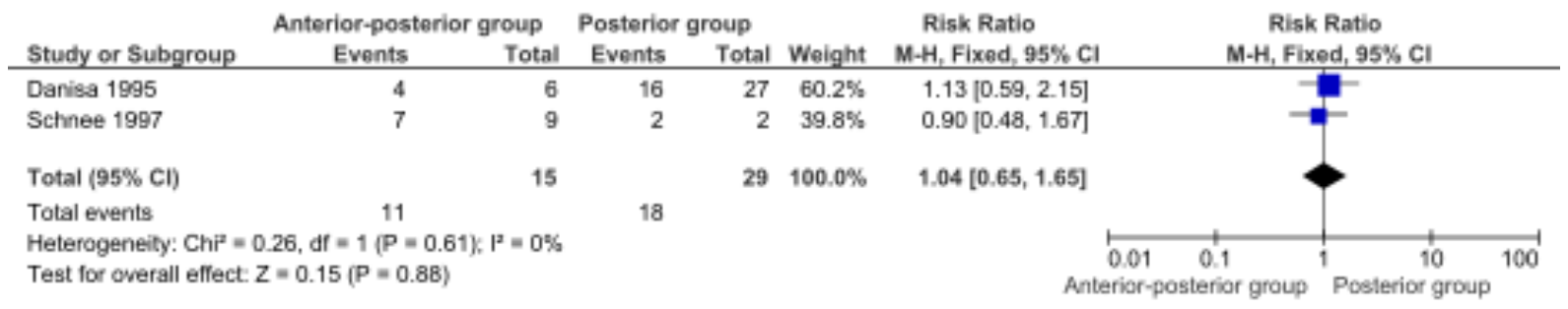

Fig. (5). Forest plot comparing anterior-posterior surgery versus posterior surgery for the outcome return to previous employment (heavy labour or sedentary).

The total charge of the hospitalization and physician visits in dollars was only retrieved from one study (Comparison 1.9: one study; 33 participants; WMD 66444.0, $95 \%$ CI 48889.19 to $83998.81 ; \mathrm{P}<.00001)$ [6]. The total charge of the hospitalization and physician visits in dollars was significantly higher in the combined anterior-posterior group.

Return to previous employment (heavy labor or sedentary) was retrieved from two studies and data were pooled (Comparison 1.10: two studies; 44 participants; RR $1.04,95 \%$ CI 0.65 to $1.65 ; \mathrm{P}=0.88)[6,11]$. Return to previous employment (heavy labor or sedentary) was not significantly different between the two approaches (Fig. 5).

Three studies were pooled for the outcome: Deep wound infection (Comparison 1.11: three studies; 90 participants; RR $0.79,95 \%$ CI 0.15 to $4.09 ; \mathrm{P}=0.78)[6,8,11]$. The outcome deep wound infection was not significantly different between the two approaches (Fig. 6).

The outcome, intra- and postoperative complications needing reoperations, was only retrieved from one study (Comparison 1.12: one study; 645 participants; RR 1.73, $95 \%$ CI 0.92 to $3.25 ; \mathrm{P}=0.09$ ) [7]. For the outcome, intraand postoperative complications needing reoperations, more complications needing reoperation in the combined anteriorposterior group.

The outcome, intra- and postoperative complications not needing reoperations, was only retrieved from one study (Comparison 1.13: one study; 645 participants; RR 0.60, 95\% CI 0.31 to $1.13 ; \mathrm{P}=0.11$ ) [7]. The outcome, intra- and postoperative complications not needing reoperations, was not significantly different between the two approaches.

The outcome Hannover spine score was only retrieved from one study (Comparison 1.14: one study; 342 participants; WMD $-4.80,95 \% \mathrm{CI}-9.70$ to $0.10 ; \mathrm{P}=.05$ ) [10]. For the outcome, Hannover spine score, worse scores were observed in the combined anterior-posterior group.
The different domains of the quality of life (SF-36) questionnaire were only retrieved from one study with 20 participants [9]. The following domains were examined: physical functioning (Comparison 1.15: WMD 8.52, 95\% CI -12.44 to $29.48 ; \quad \mathrm{P}=.43)$, physical role limitations (Comparison 1.16: WMD -1.22, 95\% CI -35.43 to 32.99 ; $\mathrm{P}=.94$ ), body pain (Comparison 1.17: WMD -7.80, 95\% CI 30.04 to $14.44 ; \mathrm{P}=.69)$, general health perceptions (Comparison 1.18: WMD 0.30 , 95\% CI -14.08 to 14.68 ; $\mathrm{P}=.97$ ), vitality (Comparison 1.19: WMD -4.10 , 95\% CI 22.34 to $14.14 ; \mathrm{P}=.44$ ), social functioning (Comparison 1.20: WMD $-3.50,95 \% \mathrm{CI}-22.14$ to $15.14 ; \mathrm{P}=.71)$, emotional role limitations (Comparison 1.21: WMD -5.57, 95\% CI -37.50 to 26.36; $\mathrm{P}=.73$ ), and mental health (Comparison 1.22: WMD $1.40,95 \% \mathrm{CI}-13.08$ to $15.88 ; \mathrm{P}=.85)$. There were no significant differences between the two approaches.

\section{Anterior-Posterior Surgery Versus Age-Referenced Controls (Norm Population)}

The different domains of the quality of life (SF-36) questionnaire were only retrieved from one study with ten participants [9]. For the domain, physical functioning (Comparison 2.1: WMD $-11.45,95 \%$ CI -24.76 to $1.86 ; \mathrm{P}=.09$ ), worse scores were observed in the combined anterior-posterior group as compared to the norm population. The domain, physical role limitations (Comparison 2.2: WMD -31.49, 95\% CI -60.06 to $-2.92 ; \mathrm{P}=.03$ ), was significantly different in the combined anterior-posterior group versus the norm population. The domains body pain (Comparison 2.3: WMD -18.20, 95\% CI -42.52 to $6.12 ; \mathrm{P}=.14)$, general health perceptions (Comparison 2.4: WMD 4.10, 95\% CI -11.78 to 19.98; $\mathrm{P}=.61$ ), vitality (Comparison 2.5: WMD $-7.43,95 \% \mathrm{CI}-21.69$ to 6.83 ; $\mathrm{P}=.31$ ), social functioning (Comparison 2.6: WMD -9.91 , $95 \%$ CI -26.11 to $6.29 ; \quad \mathrm{P}=.23)$, emotional role limitations (Comparison 2.7: WMD -16.64, 95\% CI -44.01 to 10.73 ; $\mathrm{P}=.23$ ), and mental health (Comparison 2.8: WMD 2.94, 95\% CI -9.64 to $15.52 ; \mathrm{P}=.65$ ) were all not significantly different from the norm population.

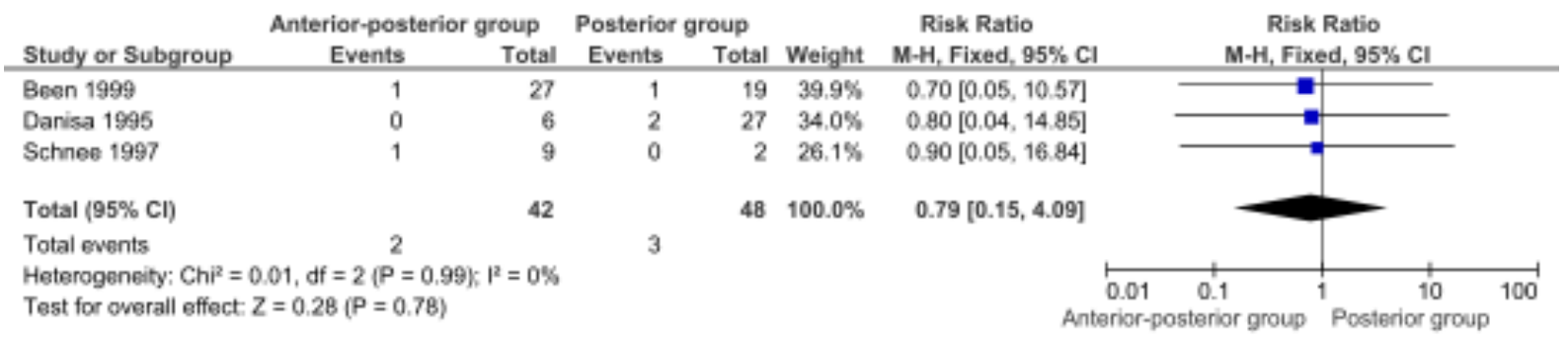

Fig. (6). Forest plot comparing anterior-posterior surgery versus posterior surgery for the outcome deep wound infection. 


\section{Posterior Surgery Versus Age-Referenced Controls (Norm Population)}

The different domains of the quality of life (SF-36) questionnaire were only retrieved from one study with ten participants [9]. For the domains, physical functioning (Comparison 3.1: WMD -19.97, 95\% CI -42.34 to 2.40; $\mathrm{P}=.08$ ) and physical role limitations (Comparison 3.2: WMD -30.27, $95 \% \mathrm{CI}-60.97$ to $0.43 ; \mathrm{P}=.05$ ), worse scores were observed in the posterior group as compared to the norm population. The domains of body pain (Comparison 3.3: WMD -10.40, 95\% CI -32.93 to $12.13 ; \mathrm{P}=.37$ ), general health perceptions (Comparison 3.4: WMD $3.80,95 \%$ CI -11.31 to $18.91 ; \mathrm{P}=.62)$, vitality (Comparison 3.5: WMD -3.33, 95\% CI -21.72 to 15.06; $\mathrm{P}=.72$ ), social functioning (Comparison 3.6: WMD -6.41, 95\% CI 24.17 to $11.35 ; \mathrm{P}=.48$ ), emotional role limitations (Comparison 3.7: WMD $-11.07,95 \% \mathrm{CI}-36.91$ to $14.77 ; \mathrm{P}=.40$ ), and mental health (Comparison 3.8: WMD 1.54, 95\% CI -13.85 to 16.93 ; $\mathrm{P}=.84$ ) were all not significantly different from the norm population.

\section{Anterior-Posterior Surgery Versus Posterior Surgery Using Data from Another Systematic Review [5]}

In the systematic review by Verlaan et al. the pooled data were not statistically analysed [5]. These authors distinguished four posterior surgery groups: posterior short-segment instrumentation, posterior long-segment instrumentation, posterior short- or long-segment instrumentation and combined anterior and posterior technique. Because of our objective, comparing the posterior technique with the combined approach, we compared the posterior short-segment instrumentation with the combined anterior and posterior technique in Verlaan's review. Verlaan's combined group also includes the data from 27 patients in the Been et al. group, which we also used [8]. Because Verlaan et al. stated that the different groups were not comparable for the preoperative Cobb's angle, we compared this angle between the combined and posterior approach [5]. A significant higher preoperative Cobb's angle in degrees was found in the combined group (Comparison 4.1: one review; 1281 participants; WMD 3.70, 95\% CI 2.20 to 5.20 ; $\mathrm{P}<.00001$ ). The postoperative kyphotic correction was significantly higher in the combined anterior-posterior group (Comparison 4.2: one review; 1281 participants; WMD 3.00 , 95\% CI 1.88 to 4.12 ; $\mathrm{P}<.00001)$. This difference is probably clinically not important. The percentage of patients with no or minimal pain at follow-up was not significantly different between the two group (91\% versus 84\%) (Comparison 4.3: one review; 387 participants; RR $1.08,95 \%$ CI 0.96 to $1.22 ; \mathrm{P}=.21$ ). The percentage of miscellaneous complications did not differ between the two approaches (4.6\% versus 2.9\%) (Comparison 4.4: one review; 1659 participants; RR $1.59,95 \%$ CI 0.73 to $3.47 ; \mathrm{P}=.24$ ).

\section{DISCUSSION}

This review includes data from five observational comparative studies, but only two studies were prospective. One multicenter study included 682 patients, of which 351 had long follow-up and so were available for our objectives. Because of this large population, the study had great influence on data analysis $[7,10]$. The other included studies had small sample sizes.

The postoperative kyphotic correction and postoperative improvement of vertebral height (saggital index) were significantly higher in the combined anterior-posterior group. The loss of this kyphotic correction and the height loss of the vertebral body (saggital index) during follow-up did not differ significantly between the two approaches. The weighted mean difference of kyphotic correction $\left(3.42^{0}\right)$ and the WMD of the height improvement (.10) are clinically unimportant. This improved kyphotic correction is not expected to be found in the current two-staged combined approach. In this technique, the kyphotic angle is first corrected during the posterior approach. During the second stage by anterior approach, the objective is only spinal fusion and not kyphotic correction. The percentage of patients with no or minimal pain at follow-up was not significantly different between the two approaches. Mean volume blood loss and total hospitalization and physician charges were significantly higher in the combined anterior-posterior group. Operative time and postoperative hospital stay were significantly longer in the combined anterior-posterior group. When thoracoscopically-assisted anterior fusion techniques are more commonly used, changes may occur in the outcomes mentioned above.

No significant differences were found for return to previous employment or for deep wound infections. A trend was found for more intra- and postoperative complications needing reoperations in the combined anterior-posterior group. No significant differences were found for intra- and postoperative complications not needing reoperations. A trend was found for worse Hannover spine score in the combined anterior-posterior group. The quality of life (SF36) domain scores were not significantly different between the two approaches. In addition, no differences were found for the two surgical approaches for the quality of life (SF-36) domain scores as compared with the norm population.

Our conclusion is that a small significant increase (probably not clinically important) in kyphotic correction and improvement of vertebral height (saggital index) for the combined anterior-posterior group is cancelled out by more blood loss, longer operation time, longer hospital stay, higher costs and a possible higher intra- and postoperative complication rate needing reoperations, as well as a potentially worse Hannover spine score.

Are the included observational studies biased by patient selection? In the multicenter study of Knop et al. only one operation technique was performed in a clinic [7, 10]. Is it possible that certain type of acute spinal fracture patients are referred to a special clinic or does every clinic get the same type of patients? The combined anterior-posterior group had significantly more preoperative neurological deficits and more type $\mathrm{C}$ fractures than the posterior group in this multicenter study. The patients with long follow-up had no differences in preoperative neurological deficit, but more type $\mathrm{C}$ fractures. In the study of Been et al. no significant differences existed for age, sex, cause of injury or fracture classification, but there were more patients with other severe traumatic injuries and less patients with fractures at the level of the thoracolumbar junction in the combined group [8]. In the study of Briem et al. the patients were matched for sex, age and radiological pattern of injury [9]. In the Danisa et al. study, the groups were similar for age, gender, level of injury, \% of canal compromise, neurological function and kyphosis preoperatively, but the sample size of the combined 
group was only six [6]. The Schnee et al. study only had a sample size of two for the posterior approach [11]. In this study, the operative approach was dependent on vertebral body height, canal compromise and kyphosis. In summary, the selection for the operation technique is biased; worse neurological and structural cases had a greater chance to undergo a combined anterior-posterior approach. Patients are selected for the anterior approach because of neurological reasons. With this approach, the spinal canal is cleared of bone fragments. However, a review article found no evidence for neurological improvement after spinal canal clearance [12]. A progressive neurological deficit still represents an indication for surgical decompression of the spinal canal. The Load Sharing Classification [13], which was developed to classify thoracolumbar fracture severity, can be used to select patients for a specific treatment for structural reasons. The different options for selection can be conservative versus operative treatment [14]; anterior versus posterior surgery [15]; anterior versus anterior-posterior combined approach [16]. The anterior approach will then be used for more comminuted fractures. The Load Sharing Classification has good intra- and inter-observer reliability [17], but has still to be validated in RCTs.

In a systematic review about the management of unstable traumatic thoracolumbar fractures without neurological deficit, the authors could not make any conclusions regarding the effectiveness of a particular kind of treatment because of the poor methodological quality of the studies [18]. Comments on this review suggested the inclusion of non-comparative observational studies [19]. In the latest edition of the Cochrane handbook, the authors stated that it may be justified to include non-randomized studies [20]. Verlaan et al. included retrospective and prospective caseseries in their systematic review, but they did not pool and statistically analyze their data because they concluded the data were too heterogeneous [5]. Analyzing their data, we found no discrepancies with our results.

It is important to emphasize that the quality of the evidence is low because of the lack of RCTs, because the observational studies used could be biased by selection, and because most studies had a small sample size, leading to a lack of power.

It is a good tradition to end a review by asking to initiate high quality RCTs for comparing the different treatment modalities. However, surgical technique for the treatment of spinal fractures is rapidly evolving; operations are more often performed with the use of a thoracoscope and surgeons often try newly developed operation techniques before comparing them in RCTs with older techniques.

\section{REFERENCES}

[1] Hu R, Mustard CA, Burns C. Epidemiology of incident spinal fracture in a complete population. Spine 1996; 21(4): 492-9.
[2] Knop C, Blauth M, Buhren V, et al. Surgical treatment of injuries of the thoracolumbar transition. 1: Epidemiology. Unfallchirurg 1999; 102(12): 924-35.

[3] Denis F. The three column spine and its significance in the classification of acute thoracolumbar spinal injuries. Spine 1983; 8(8): 817-31.

[4] Yi L, Jingping B, Gele J, Baoleri X, Taixiang W. Operative versus non-operative treatment for thoracolumbar burst fractures without neurological deficit. Cochrane Database Syst Rev 2006; (4): CD005079.

[5] Verlaan JJ, Diekerhof CH, Buskens E, et al. Surgical treatment of traumatic fractures of the thoracic and lumbar spine: A systematic review of the literature on techniques, complications, and outcome. Spine 2004; 29(7): 803-14.

[6] Danisa OA, Shaffrey CI, Jane JA, et al. Surgical approaches for the correction of unstable thoracolumbar burst fractures: A retrospective analysis of treatment outcomes. J Neurosurg 1995; 83(6): 977-83.

[7] Knop C, Blauth M, Buhren V, et al. Surgical treatment of injuries of the thoracolumbar transition. 2: operation and roentgenologic findings. Unfallchirurg 2000; 103(12): 1032-47.

[8] Been HD, Bouma GJ. Comparison of two types of surgery for thoraco-lumbar burst fractures: Combined anterior and posterior stabilisation $v s$ posterior instrumentation only. Acta Neurochir (Wien ) 1999; 141(4): 349-57.

[9] Briem D, Lehmann W, Ruecker AH, Windolf J, Rueger JM, Linhart W. Factors influencing the quality of life after burst fractures of the thoracolumbar transition. Arch Orthop Trauma Surg 2004; 124(7): 461-8.

[10] Knop C, Blauth M, Buhren V, et al. Surgical treatment of injuries of the thoracolumbar transition. 3: Follow-up examination. Results of a prospective multi-center study by the "Spinal" Study Group of the German Society of Trauma Surgery. Unfallchirurg 2001; 104(7): 583-600.

[11] Schnee CL, Ansell LV. Selection criteria and outcome of operative approaches for thoracolumbar burst fractures with and without neurological deficit. J Neurosurg 1997; 86(1): 48-55.

[12] Boerger TO, Limb D, Dickson RA. Does 'canal clearance' affect neurological outcome after thoracolumbar burst fractures? J Bone Joint Surg Br 2000; 82(5): 629-35.

[13] McCormack T, Karaikovic E, Gaines RW. The load sharing classification of spine fractures. Spine 1994; 19(15): 1741-4.

[14] Dai LY, Jiang LS, Jiang SD. Conservative treatment of thoracolumbar burst fractures: A long-term follow-up results with special reference to the load sharing classification. Spine 2008; 33(23): 2536-44.

[15] Parker JW, Lane JR, Karaikovic EE, Gaines RW. Successful shortsegment instrumentation and fusion for thoracolumbar spine fractures: A consecutive 41/2-year series. Spine 2000; 25(9): 115770 .

[16] Aligizakis AC, Katonis PG, Sapkas G, et al. Gertzbein and load sharing classifications for unstable thoracolumbar fractures. Clin Orthop Relat Res 2003; (411): 77-85.

[17] Dai LY, Jin WJ. Interobserver and intraobserver reliability in the load sharing classification of the assessment of thoracolumbar burst fractures. Spine $2005 ; 30(3)$ : 354-8.

[18] van der Roer N, de Lange ES, Bakker FC, et al. Management of traumatic thoracolumbar fractures: A systematic review of the literature. Eur Spine J 2005; 14(6): 527-34.

[19] Knop C, Blauth M. Comments on "Management of traumatic thoracolumbar fractures..." Eur Spine J 2005; 14(6): 535.

[20] Reeves BC, Deeks JJ, Higgens JPT, Wells GA. Including nonrandomized studies. In: Higgens JPT, Green S, Eds. Cochrane Handbook for Systematic Reviews of Interventions. Version 5.0.0 [updated February 2008]. The Cochrane Collaboration. 